\title{
IMMUNOHISTOCHEMICAL AND POLYMERASE CHAIN REACTION STUDY ON EXPRESSION OF HPV AND HSV AND ITS HISTOPATHOLOGICAL PATTERN CORRELATION IN CERVICAL LESIONS
}

\author{
Smita Chouhan'1, Reeni Malik², Rajendra Kumar Nigam³, Pramila Jain ${ }^{4}$ \\ 1 Junior Resident, Department of Pathology, Gandhi Medical College, Bhopal, M. P. \\ 2 Professor and HOD, Department of Pathology, Gandhi Medical College, Bhopal, M. P. \\ ${ }^{3}$ Professor and HOD, Department of Pathology, Gandhi Medical College, Bhopal, M. P. \\ ${ }^{4}$ Associate Professor, Department of Pathology, Gandhi Medical College, Bhopal, M. P.
}

ABSTRACT
BACKGROUND
Cervical cancer has a major impact on developing countries, where screening programmes are not well established or effective.

AIM

This study aims to detect HPV and HSV in cervical lesions using Immunohistochemistry and Polymerase chain reaction.

\section{SETTINGS AND DESIGN}

85 biopsy samples were obtained from out and inpatients attending Gynaecology Department in Gandhi Medical College and associated hospital, Bhopal between January - August 2015.

\section{MATERIALS AND METHODS}

Two biopsy specimens of the cervix were simultaneously collected from the same patient; one for histopathological examination and other for polymerase chain reaction. The samples were graded as chronic cervicitis, Cervical Intraepithelial Neoplasia (CIN) I, II, III, and Squamous Cell Carcinoma (SCC) and cervical adenocarcinoma by pathologist in Department of Pathology.

\section{RESULTS}

Out of 85 cervical biopsies, HPV (IHC) positivity was maximum for chronic cervicitis with dysplasia (77.8\%). IHC using HSV in cervical lesions showed $45.2 \%$ positivity in chronic cervicitis; $44.4 \%$ in chronic cervicitis with dysplasia and $21.9 \%$ in squamous cell carcinoma.

\section{CONCLUSION}

This study reveals a significant detection of HPV in the individuals with pre-cancerous lesions by the use of advanced techniques such as IHC and PCR.

\section{KEYWORDS}

Cervical Intraepithelial Neoplasia, Human Papillomavirus, Squamous Cell Carcinoma, Immunohistochemistry, Polymerase Chain Reaction.

HOW TO CITE THIS ARTICLE: Chouhan S, Malik R, Nigam RK, et al. Immunohistochemical and polymerase chain reaction study on expression of HPV and HSV and its histopathological pattern correlation in cervical lesions. J. Evolution Med. Dent. Sci. 2016;5(71): 5190-5195, DOI: $10.14260 /$ jemds/2016/1177

\section{INTRODUCTION \\ Cervical cancer is the fifth most common cancer in humans and the sexually transmitted human papillomavirus (HPV) infection is the most important risk factor for cervical intraepithelial neoplasia and invasive cervical cancer. ${ }^{1}$ The worldwide incidence of cervical cancer is approximately 510,000 cases with approximately 288,000 deaths worldwide. ${ }^{2}$ Indian women faces a $2.5 \%$ cumulative lifetime risk and $1.4 \%$ cumulative death risk from cervical cancer. ${ }^{3}$ Unlike many other cancers, cervical cancer occurs early and strikes at the productive period of a woman's life. The incidence rises in 30-34 years of age and peaks at 55-65 years with a median age of 38 years (Age 21-67 years)}

Financial or Other, Competing Interest: None.

Submission 25-06-2016, Peer Review 19-08-2016,

Acceptance 26-08-2016, Published 03-09-2016.

Corresponding Author:

Dr. Smita Chouhan

C/o. Mr. N. S. Chouhan,

\#40, Shukla Colony,

Shantiniketan,

Mandsaur-458001, M. P.

E-mail: smitachouhan84@gmail.com

DOI: $10.14260 /$ jemds/2016/1177
Estimates suggest that more than $80 \%$ of the sexually active women acquire genital HPV by 50 years of age. The highest prevalence of HPV infection is seen soon after the onset of sexual activities.

Other factors postulated to play a role in the development of cervical cancer include human cytomegalovirus, human herpesvirus $6(18,19)$ human immunodeficiency virus. HSV-2 is spread primarily by sexual contact, and therefore the risk factors are similar to those of other sexually transmitted diseases like HPV. ${ }^{4}$ The biological interaction between HSV-2 and HPV-16 or HPV-18 occurs during the development of cervical carcinoma. ${ }^{5}$ But the contribution by the risk associated with HPV infection are not included in these studies.

This study examines the presence of HPV and HSV in cervical biopsy using immunohistochemistry and Polymerase Chain Reaction (PCR) and to study the interaction between HPV and HSV.

\section{MATERIALS AND METHODS}

This prospective randomised study was undertaken at Gandhi Medical College and associated Hospital in 85 patients from Jan. 2014 to Aug. 2015 to evaluate the HPV and HSV 
positivity in cervical lesions to measure association with risk factor and to evaluate co-association between HPV and HSV by immunohistochemistry and polymerase chain reaction. Two samples were simultaneously collected from the same patient, one for histopathology and IHC and the other for PCR.

For histopathology 4 um thick sections were taken, after that dewaxing and hydration was done using xylene and alcohol. Staining was done using Harris' alum haematoxylin. Then after dehydration using alcohol and subsequent mounting was done. ${ }^{6}$

\section{IHC STAINING PROCEDURE ${ }^{7}$}

Immunohistochemistry was performed on 85 samples. For conducting immunohistochemical experiments, the kits and other chemicals were from BioGenex.

1. Firstly, 4 um sections of formalin-fixed, paraffin embedded tissues were cut and placed on clean microscopic slides.

2. The sections were dewaxed in xylene, rehydrated in graded alcohol and rinsed in water.

3. For antigen retrieval - sections were immersed in citrate buffer, pH 6.0, in a high pressure cooker for 20 minutes, the tissue sections were cooled under tap water for 10 minutes.

4. A peroxidase block reagent was applied on the tissue and it was incubated for 5-10 minutes at room temperature.

5. Then a power block reagent was added, after draining out the slides and incubated for 15 minutes at room temperature.

6. An appropriate volume of mouse monoclonal antibody HPV and HSV was added for one hour on the specimen and then with an appropriate volume of a secondary antibody, i.e. super enhancer reagent, it was incubated for 30 minutes followed by rinsing with Tris-buffered saline, pH 7.4 for 10 minutes.

7. Peroxidase was added to it and was incubated at room temperature for 30 minutes followed by rinsing with Tris-buffered saline.

8. The negative control consisted of the same section where the diluents without primary antibody were applied. The slides were mounted and viewed in light microscopy.

\section{RESULT}

Nucleus-dark brown; Cytoplasm-brown. Any nuclear staining was considered a positive result, regardless of the quantity of cells having expression.

\section{HPV AND HSV DETECTION USING POLYMERASE CHAIN REACTION8 \\ Sample Preparation}

For sample preparation, the sample is mixed with viral lysate provided by BIOPAP kit. This process liberates the DNA present in tissue.

\section{Target Selection}

The sample obtained is mixed with target HPV sequences; obtained from the tests done on HPV genome for tested generic genotypes (GEN1 and GEN2 primers), and oncogenic HPV genotypes (ONC1 and ONC2). This selected regions have a high degree of conservation between the tested genotypes. Pair 1 (GEN1 and GEN2) defines a segment of approximately
$400 \mathrm{bp}$, while Pair 2 (ONC1 and ONC2) defines a sequence of approximately $250 \mathrm{bp}$ in oncogenic HPV genotypes.

\section{Amplification}

The amplification field has enzyme DNA polymerase, magnesium and other salts. DNA is amplified with a thermostable DNA polymerase from thermos in the presence of magnesium and salt and ionic strength conditions. After hybridisation of primer pairs has taken place. Then in the presence of triphosphate deoxynucleotides, the DNA polymerase extends the primer and forms a DNA strand which is complementary to the template DNA. This cyclic repetition of process results in amplification of the sequences originally present in the sample included between the primer pairs.

\section{Detection}

This amplified product is subjected to agarose gel electrophoresis containing fluorescent dye ethidium bromide. This fluorescent dye produces fluorescence when the tincture molecule detaches from dye after formation of complementary pair.

\section{Ethical Consideration}

The study was approved by Institutional Ethics Committee of Gandhi Medical College, Bhopal (M.P.) with letter no. - 10308 - 09/MC/7/2015 dated 11.5.15.

\section{STATISTICAL ANALYSIS}

A total of 85 cases were studied. Data was entered in Microsoft Office Excel Work Sheets. Then data was analysed using appropriate statistical tests using software Epi-Info and SPSS and sofastats. A total of 85 cases were studied. The data was represented in tables and charts. Chi square test was applied for qualitative data. The test was considered significant, if $\mathrm{p}<0.05$ at $95 \%$ confidence level.

\section{RESULTS}

Out of 85 patients' cases - Chronic cervicitis (49.41\%), Squamous cell carcinoma (37.65\%), Chronic cervicitis with dysplasia (10.59\%) and Adenocarcinoma of cervix (2.35\%). Maximum cases of chronic cervicitis were in the age group 41-50 years; chronic cervicitis with dysplasia in 31-40 years while that of squamous cell carcinoma were in 41-50 years' age group.

White discharge was the chief complaint in patients with chronic cervicitis. Bleeding per vaginum is the most common presenting complaint in patients with carcinoma cervix. Patients with chronic cervicitis with dysplasia presented with both white discharge (5/9) and bleeding per vaginum (4/9).

\section{Risk Factor Evaluation}

Maximum cases of squamous cell carcinoma 61.5\% (24/32) were seen in the females married less than 18 years of age $(\mathrm{p}<.001)$. Maximum cases of squamous cell carcinoma $(61.5 \%)$ were seen in females who conceived at less than 19 years of age $(\mathrm{p}<.001)$.

Maximum cases of squamous cell carcinoma $68.75 \%$ $(22 / 32)$ were in females with parity $>3(p=.005)$.

Cases of squamous cell carcinoma is more in smokers. $(\mathrm{p}=.02)$.

The presence of viral infection was evidenced by a strong nuclear expression of viral infection marker (HPV and HSV). 
Maximum cases of HPV and HSV positivity using immunohistochemistry and polymerase chain reaction were in the age group 41-50 followed by 31-40 years of age range.

Immunohistochemistry using HPV antibody in cervical lesions showed that HPV (IHC) positivity was maximum for chronic cervicitis with dysplasia(77.8\%); $52.4 \%$ for chronic cervicitis; $34,4 \%$ for squamous cell carcinoma and only one case for adenocarcinoma cervix was positive (Table 1).

IHC using HSV in cervical lesions showed $45.2 \%$ positivity in chronic cervicitis; $44.4 \%$ in chronic cervicitis with dysplasia and $21.9 \%$ in squamous cell carcinoma (Table 2).

Maximum cases of HPV positivity using PCR were that of chronic cervicitis with dysplasia $44.4 \%$ followed by squamous cell carcinoma $43.8 \%$. None of the cases were positive for HSV using PCR (Table 3).

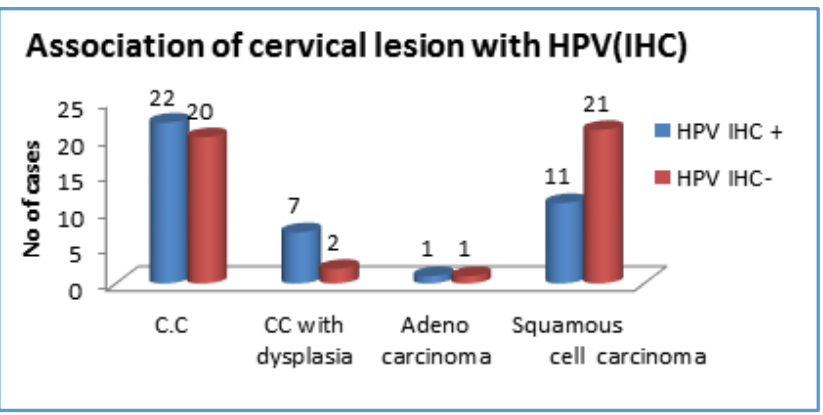

Table 1: Association of Cervical Lesion with HPV $\{I H C\}$

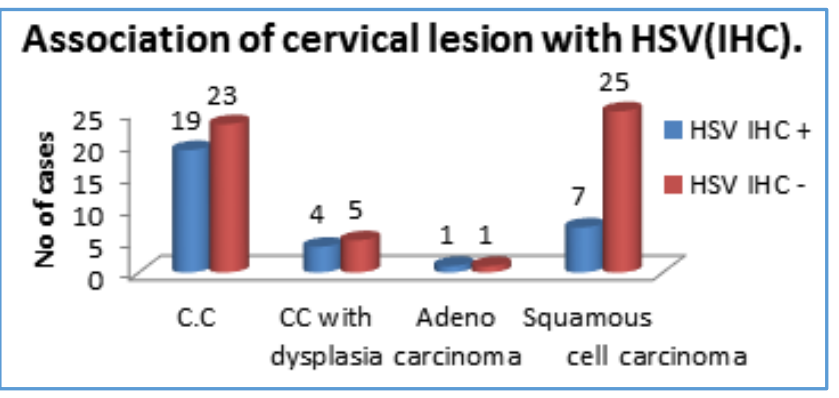

Table 2: Association of Cervical Lesion with $\mathrm{HSV}\{\mathrm{IHC}\}$

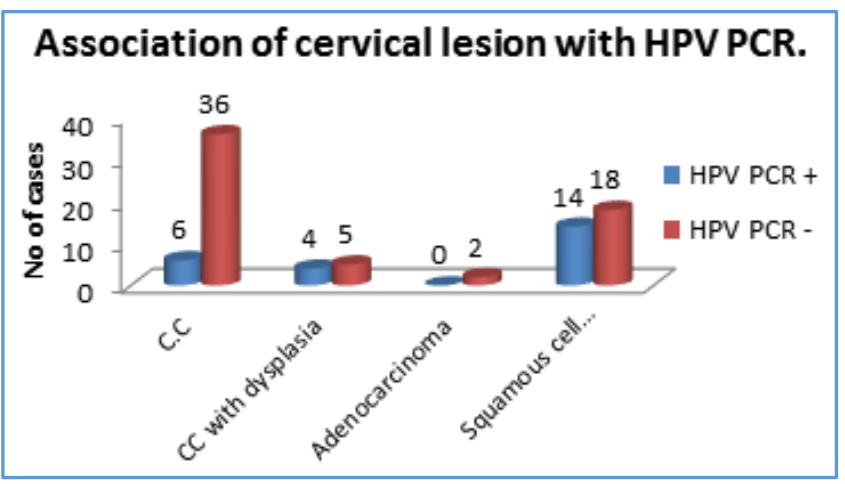

Table 3: Association of Cervical Lesion with HPV PCR

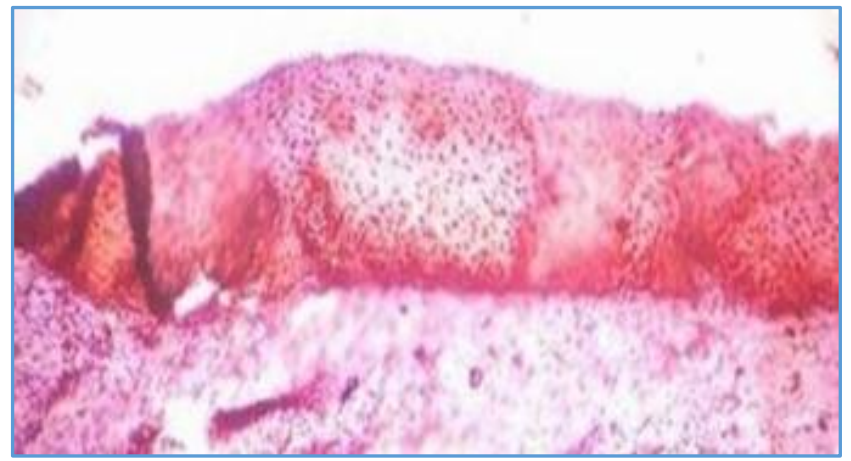

IHC Image 1: HPV Positivity in Chronic Cervicitis

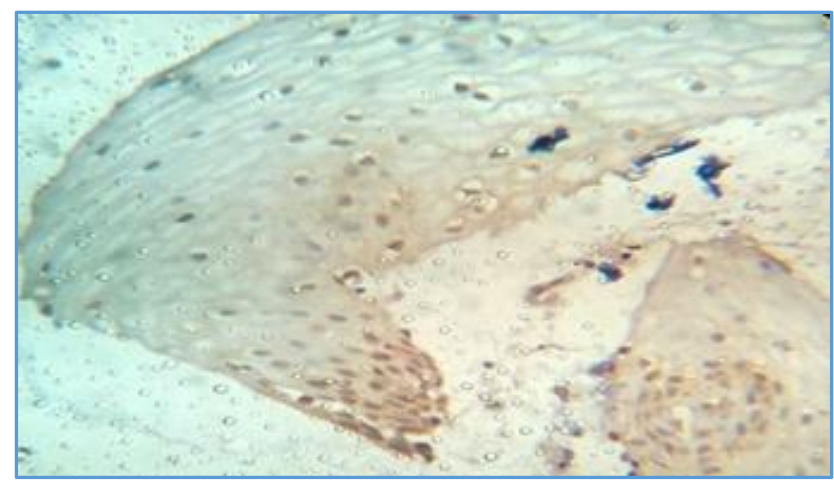

IHC Image 2: HPV Positivity (Brown Nuclear Staining) in Cervical Dysplasia

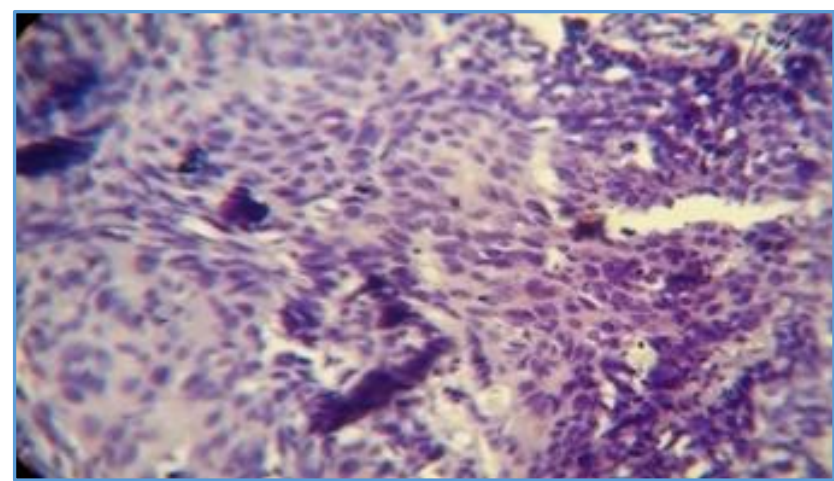

IHC Image 3: HPV Negative in Squamous Cell Carcinoma

\section{DISCUSSION}

The purpose of present study was to assess prevalence of HPV and HSV infection; co-infection and association with risk factors in women with cervical lesions using immunohistochemistry and polymerase chain reaction.

In our study there were maximum cases of chronic cervicitis (49.41\%) comparable with Atul Jain, ${ }^{9}$ who reported benign lesions to be the majority of cases in their studies on morphological spectrum of lesions of uterine cervix, although number of cases varies.

Cases of chronic cervicitis were found in 21-60 years' age range with majority of cases in 41-50 years' age range; similar to morphological spectrum of non-neoplastic lesions of cervix reported by Aravind Papillady. ${ }^{10}$

Maximum cases of HPV positivity by immunohistochemistry and polymerase chain reaction were in the age group of 41-50 years followed by 31-40 years' age group. These findings were similar to Nawalakha and Mathur 
et al, ${ }^{11}$ who reported maximum incidence of HPV positivity in the age group of 40-49 years.

In our study, maximum incidence of squamous cell carcinoma of cervix was seen in women with parity $>3$. This was similar to the previous study done by Aikat, 12 Shrivastav, ${ }^{13}$ Mishra et al ${ }^{14}$ and Juneja et al. ${ }^{15}$

A significant association between smoking and cervical carcinoma was noted $(\mathrm{p}<.02)$; similar to those reported by Szarewski et al,16 Deacon et al,17 Plummer et al ${ }^{18}$ and Castellsagué et al.19

In our study, there is a significant association among incidence of cervical carcinoma among women with low socioeconomic status (III and IV) $(\mathrm{p}<.01)$. Similar findings were reported by Coppleson ${ }^{20}$ and Roy et al. ${ }^{21}$

In our study no significant association with use of oral contraceptives was seen with cervical carcinoma, similar to Kruger-Kjaer et al.22

In our study maximum cases of squamous cell carcinoma of cervix; seen in patients married at an early age; before 18 years of age and who conceived before the age of 19 years. These findings were similar to those reported by Nawalakha and Mathur et al.11

In our study, HPV positivity with IHC was maximum for Chronic Cervicitis with dysplasia $77.8 \%, 52.4 \%$ for chronic cervicitis and $34.4 \%$ for Squamous Cell Carcinoma (Table 1).

This is comparable with studies done by Hoepfner ${ }^{23}$ and Meenu Pujani. ${ }^{24}$

In the benign lesions caused by HPV the viral DNA is located extrachromosomally in the nucleus, whereas in highgrade intraepithelial neoplasias and cancers HPV DNA is generally integrated into the host genome. In some cases, episomal and integrated HPV DNAs are carried simultaneously in the host cell.25,26 Integration of HPV DNA into host DNA disrupts or deletes the E2 open reading frames, which results in loss of its expression. ${ }^{27}$

The various molecular alteration that results in absence of capsid proteins expression in LSIL - associated HSIL/CIN 3 are integration, gene methylation, etc. ${ }^{28}$ However, the exact mechanism responsible for the loss of L1 and L2 expression in these lesions is not known.

Moreover, the factors that can be attributed to it includes viral load in the cervical lesions. High viral load is often considered to be indicative of persistent infection and progression, while low viral load has been interpreted to reflect HPV viral clearance. A pitfall of this concept is that CIN1 lesions reflect productive infections and may have thousands of viral copies/cell in upper layers of the cervical mucosa, but CIN2/3 and SCC lesions may have as low as a single copy of viral DNA/cell, because their DNA is integrated into the host genome and may not be supporting the viral replication. Thus, there is a likelihood of increased risk of false negative HPV test results in high-grade lesions compared to low-grade lesions. Thus, the high-grade lesion cell sample should also include cells derived from a coexisting low-grade productive infection.

The higher positivity in pre-invasive lesions of cervix (78.5\%) in comparison to diagnosed cases of carcinoma cervix $(37 \%)$ could be explained by the fact that $\mathrm{L}_{1}$ gene is predominantly expressed in the nuclei of koilocytes, and its expression is limited to more differentiated cells. So, it can be hypothesised that with progression from precancerous to cancerous state (i.e. loss of differentiation), there is relative decrease of $\mathrm{L}_{1}$ capsid protein expression.

In chronic cervicitis HPV positivity by PCR was $14.3 \%$, similar to that reported by M. Soma ${ }^{29} 44.4 \%$ in intraepithelial neoplasia and $43.8 \%$ in squamous cell carcinoma. These results were similar to that of Sunagul, Sheeba Murad. 30 They reported HPV 16 and 18 in $42 \%$ and $45 \%$ of squamous cell carcinoma.

Though few factors which may explain the case in which no HPV DNA is detectable include improper sampling; disruption of HPV by integration events; the existence of still unidentified HPVs; sensitivity of the method and the mechanism of transformation. ${ }^{31}$

In our study HPV positivity by PCR was $14.3 \%$ in chronic cervicitis; $44.4 \%$ in intraepithelial neoplasia, $43.8 \%$ in squamous cell carcinoma (Table 3 ).

\section{Using PCR}

We did not achieve the proportions mentioned in the literature. A possible explanation for this underestimation might be the existence of very few HPV infected cells or their total absence from the site of excision of the cervical samples taken for HPV testing.

Similar conclusions are drawn from the follow-up evaluation of the cancers in the international study that were initially thought to be HPV-negative indicated either that they were false-negative results or that the DNA in the specimens was too degraded for the negative results to be deemed reliable. 32

In addition some of the samples exhibiting discordance may have infection with HPV types not amplified by the used primers, but still detectable by the immunohistochemistry cocktails. Finally, different demographic parameters between studies may affect the prevalence of latent infection and the sensitivity and specificity of the two tests.

In the present study, HSV infection was not associated with any risk of development of cervical carcinoma ( $p>0.5)$ (Table 2). Similarly, Clinton Jones ${ }^{33}$ and Farivar ${ }^{34}$ found no association of HSV with cervical cancer.

In our study none of the cases were positive for HSV by PCR, similar to Farivar TN. ${ }^{34}$ A literature review on data for the prevalence of HSV using IHC and PCR in India found no earlier publications. Moreover, the sample size was too small to achieve significant association.

In our study, no significant association between squamous cell carcinoma and HPV and HSV co-infection was seen ( $p>0.5$ ). Women with HPV had an HSV-2 rate of $12.5 \%$, whereas in the HPV-negative group the rate was $15 \%$. Similarly, Thaís Duquia Moraes Caldeira ${ }^{35}$ found no association between HPV and HSV co-infection nor a higher risk of intraepithelial lesions in the HSV-2 positive group.

\section{CONCLUSION}

The goals of this study were to define the most efficient method for evaluation of high risk for developing cervical cancer to reduce the inherent errors of each screening methodology applied and to validate the most favourable combination of methods in terms of efficacy and efficiency for the detection of the disease.

This study concurrently evaluated two different methods for the detection of CIN or cervical cancer, namely immunohistochemical marker (HPV and HSV) and molecular 
typing in cervical biopsy samples: each in comparison with histological diagnosis.

This study suggests that there must be other co-factors involved in cervical carcinogenesis as well. HPV and HSV types not identified by known primers used in PCR needs further research and evaluation.

\section{ACKNOWLEDGMENT}

Sincere thanks to Dr. Ramnani, Mr. Atul Shrivastav, Mr. B. K. Shrivastav and Mr. A. Gurjar.

\section{REFERENCES}

1. Schiffman M, Castle PE, Jeronimo J, et al. Human papillomavirus and cervical cancer. Lancet 2007;370(9590):890-907.

2. Sankaranarayanan R, Ferlay J. Worldwide burden of gynecological cancer: the size of the problem. Best Pract Res Clin Obstet Gynaecol 2006;20(2):207-25.

3. World Health Organization. World Health Organization. 2016 [cited 1 May 2008]. Available from: http://www.who.int

4. Stavraky KM, Rawls WE, Chiavetta J, et al. Sexual and socioeconomic factors affecting the risk of past infections with herpes simplex virus type 2. Am J Epidemiol 1983;118(1):109-21.

5. Hildesheim A, Mann V, Brinton LA, et al. Herpes simplex virus type 2: a possible interaction with human papillomavirus types $16 / 18$ in the development of invasive cervical cancer. Int J Cancer 1991;49(3):335-40.

6. Layton C, Suvarna SK, Bancroft JD. Theory and practice of histological techniques, expert consult Suvarna. Churchill Livingstone Elsevier 2013:NLM ID: 101599346.

7. BioGenex, Molecular Pathology Lab, miRNA, MicroRNA, Immunohistochemistry, IHC, Cell Staining, Tissue Processing, In Situ PCR, Special Stains, Primary Antibodies, Panel Markers, IHC, ISH | BioGenex US [Internet]. Biogenex.com. 2016 [cited 6 May 2010]. Available from: https://biogenex.com/

8. Empresalideren PCR y productos de laboratoriobiotools. Biotools.eu. 2016 [cited 25 July 2016]. Available from: http://www.biotools.eu

9. Jain A, Jain R, Iqbal B, et al. Histopathological study of tumours of cervix. Advances in cancer research therapy 2014. Available from: http://www.advancejournals.org.

10. Pallipady A, Illanthody S, Vaidya R, et al. A clinicomorphological spectrum of the non-neoplastic lesions of the uterine cervix at AJ Hospital, Mangalore. Indian J Pathol Microbiol 2000;43(10):23-2. (www.jcdr.net/articles/PDF/1289/1616)

11. Nawalakha PC. Carcinoma of uterine cervix. A clinical study of 1692 cases. J Obst \& Gynae India 1977;(27):794-53.

12. Aikat M, Gupta S, Aikat BK. Critical evaluation of cervical cytology. Indian J Med Res 1974;62(5):655-61.

13. Shrivastav P, Jairaj P, Balasubramaniam N, et al. Selective screening for cancer of the cervix uteri in South Indian women. Int J Gynaecol Obstet 1986;24(5):337-42.

14. Mishra NK, Sinha TK. Cytologic screening for the detection of cancer in the uterine cervix-a survey in Patna (India). Cancer Lett 1990;52(1):21-7.
15. Juneja A, Murthy NS, Sharma S, et al. Selective cervical cytology screening: discriminant analysis approach. Neoplasma 1993;40(6):401-4.

16. Szarewski A, Cuzick J. Smoking and cervical cancer: a review of the evidence. J Epidemiol Biostat 1998;3:22956.

17. Deacon JM, Evans CD, Yule R, et al. Sexual behaviour and smoking as determinants of cervical HPV infection and of CIN3 among those infected: a case-control study nested within the Manchester cohort. Br J Cancer 2000;83(11):1565-72.

18. Plummer M, Herrero R, Franceschi S, et al. Smoking and cervical cancer: pooled analysis of the IARC multicentric case-control study. Cancer Causes Control 2003;14(9):805-14.

19. Castellsagué $X$, Muñoz N. Cofactors in human papillomavirus carcinogenesis-role of parity, oral contraceptives, and tobacco smoking. J Natl Cancer Inst Monogr 2003;31:20-8.

20. Coppleson LW, Brown B. Observations on a model of the biology of carcinoma of the cervix: a poor fit between observation and theory. Am J Obstet Gynecol 1975;122(1):127-36.

21. Roy A, Dutta K, Majumdar J, et al. Cervical cytology screening in Calcutta and adjoining areas with special reference to carcinoma of the uterine cervix. Indian J Public Health 1990;34(2):98-106.

22. Krüger-Kjaer S, Van Den Brule AJ, Svare EI, et al. Different risk factor patterns for high-grade and lowgrade intraepithelial lesions on the cervix among HPVpositive and HPV-negative young women. Int J Cancer 1998;76(5):613-9.

23. Hoepfner I, Löning T. Human papillomavirus (HPV) infection of cervical lesions detected by immunehistochemistry and in situ hybridization. Cancer Detect Prev 1986;9(3-4):293-301.

24. Pujani M, Singh K, Pujani M. Correlation of human papilloma virus presence with precancerous and cancerous lesions of uterine cervix by immunohistochemistry. Tropical of Annals Medicine 2012;5(4):313-6.

25. Hausen ZH. Papillomaviruses in the causation of human cancers-a brief historical account. Virology 2009;384(2):260-5.

26. Ham J, Dostatni N, Arnos F, et al. Several different upstream promoter elements can potentiate transactivation by the BPV-1E2 protein. EMBOJ 1991;10(10):2931-40.

27. Munoz N, Bosch FX, de Sanjose S, et al. The role of HPV in the etiology of cervical cancer. Mutat Res 1994;305(2):293-301.

28. Bosch FX, Lorincz A, Munoz N, et al. The causal relation between human papillomavirus and cervical cancer. Journal of Clinical Pathology 2002;55(4):244-65.

29. Soma M, Kamaraj S. Detection of human papillomavirus in cervical gradings by immunohistochemistry and typing of HPV 16 and 18 in high-grades by polymerase chain reaction. J Lab Physicians 2010;2(1):31-6. 
30. Gul S, Murad S, Javed A. Prevalence of high risk human papillomavirus in cervical dysplasia and cancer samples from twin cities in Pakistan. International Journal of Infectious Diseases 2015;34:14-9.

31. Walboomers JM, Meijer CJ. Do HPV-negative cervical carcinoma exist? J Pathol 1997;181(3):253-4.

32. Ho GY, Bierman R, Beardsley L, et al. Natural history of cervicovaginal papillomavirus

infection in young women. $\mathrm{N}$ Eng $\mathrm{J}$ Med 1998;338(7):423-8.

33. Jones C, Zhu F, Dhanwada KR. Analysis of a herpes simplex virus 2 fragment from the open reading frame of the large subunit of ribonucleotide reductase with transcriptional regulatory activity. DNA Cell Biol 1993;12(2):127-37.
34. Farivar TN, Johari P, Shafei S, et al. Lack of association between herpes simplex virus type 2 infection and cervical cancer-TaqMan real time PCR assay findings. Asian Pac J Cancer Prev 2012;13(1):339-42.

35. Caldeira TD, Goncalves CV, Oliveira GR, et al. Prevalence of herpes simplex virus type 2 and risk factors associated with this infection in women in southern Brazil. Rev Inst Med Trop Sao Paulo 2013;55(5):315-21. 